\title{
Synthesis of Poly(paraphenylene vinylene)-Polystyrene- Based Rod-Coil Block Copolymer by Atom Transfer Radical Polymerization: Toward a Self-Organized Lamellar Semiconducting Material
}

\author{
Cyril Brochon ${ }_{1}^{1}$ Nicolas Sary, ${ }^{2}$ Raffaele Mezzenga, ${ }^{2,3}$ Chheng Ngov, ${ }^{1}$ Fanny Richard, ${ }^{1}$ \\ Michaël May, ${ }^{1}$ Georges Hadziioannou ${ }^{1}$ \\ ${ }^{1}$ Laboratoire d'Ingénierie des Polymères pour les Hautes Technologies, UMR 7165, Université Louis Pasteur, \\ Ecole Européenne de Chimie, Polymères et Matériaux, 25, Rue Becquerel, 67000 Strasbourg, France \\ ${ }^{2}$ Department of Physics and Fribourg Center for Nanomaterials, University of Fribourg, Ch. Musée 3, CH-1700, \\ Fribourg, Switzerland \\ ${ }^{3}$ Nestlé Research Center, Vers-Chez-Les-Blanc, 1000 Lausanne 26, Switzerland
}

\begin{abstract}
Atom transfer radical polymerization (ATRP) was used as a versatile route to well-defined poly(diethylhexyl-p-phenylenevinylene- $b$-styrene) (PPV-b-PS) semiconducting block copolymers. For this purpose, original conjugated macroinitiators were synthesized from DEH-PPV and further used for the copolymerization reaction. The microphase-separated morphologies obtained with the semiconducting PPV-b-
\end{abstract}

\section{INTRODUCTION}

Increasing energy needs have generated a growing interest for polymer materials and their use in photovoltaic devices. Conjugated polymers or oligomers are promising organic semiconducting materials for the elaboration of easy to process low-cost solar cells. ${ }^{1-7}$ In organic semiconducting materials, a photoexcitation generates excitons needed to be separated in free charges. ${ }^{8}$ The exciton separation is promoted at the interface of an electron acceptor and an electron donor materials. As a consequence, the morphology fine tuning of the devices active layer is crucial and requires a nanometer size lamellar, columnar, or interpenetrated network structures. Block copolymers are known for their microphaseseparated structures with nanometer size characteristic length scales. ${ }^{9}$ Thus, they are promising candidate materials for designing the active material of the organic photovoltaic devices with desired functional structure. ${ }^{10-15}$

Recently, block copolymers with a conjugated block as electron donor (the rod), and a second flexible block which could be functionalized to be an fr).

Correspondence to: C. Brochon (brochonc@ecpm.u-strasbg.
PS block copolymer fulfill the basic structural requirements required to build efficient organic photovoltaic devices. $\odot 2008$ Wiley Periodicals, Inc. J Appl Polym Sci 110: 3664-3670, 2008

Key words: PPV; semiconducting polymer; ATRP; rod-coil block copolymer; self-assembly; photovoltaic polymer materials

electron acceptor (the coil) have been proposed. Numerous semiconducting rod-coil block copolymers have been proposed, using a conjugated block (the donor unit) as initiator (macroinitiator), based on poly(para phenylene vinylene) (PPV), ${ }^{13,16-20}$ polythiophene, ${ }^{21,22}$ polyfluorene, ${ }^{23,24}$ poly(thienylene vinylene) ${ }_{1}{ }^{25}$ or oligomers, ${ }^{26,27}$ provided that functional monomers can be introduced during the copolymerization reaction of the second block, allowing the further grafting of an acceptor group, such as $\mathrm{C}_{60}$, to the coil block (the acceptor unit). ${ }^{13,16,20}$

The morphology of PPV-based model rod-coil block copolymers being a key issue their microphase separation properties have been recently studied. ${ }^{14,15,28}$ These materials have been obtained either by anionic polymerization, ${ }^{14,15}$ which is not suitable for the introduction of functional monomers allowing grafting of acceptor moieties, or by nitroxyde mediated radical polymerization (NMRP). ${ }^{28}$ The NMRP synthetic method works only at high temperature, where side reactions on PPV block can occur. Thus, the NMRP is not a very efficient and tolerant polymerization method, several useful monomers such as methacrylates cannot be used..$^{29}$ In an effort to use efficient and versatile synthetic pathways for the synthesis of block copolymers for photovoltaic materials, it is proposed here the use of atom transfer radical polymerization (ATRP) for the synthesis of a model block copolymers. ${ }^{30}$ This method is a 
well-established controlled/"living" radical polymerization requiring only mild conditions and exhibiting compatibility with a wide range of functional monomers. This way was recently used on PPV-based block copolymers with methyl methacrylate as monomer for the coil block. ${ }^{31}$

The first objective here is to synthesize in a simple way, rod-coil conjugated block copolymers. The second objective is to show that these copolymers selforganize in a good way to obtained lamellar or cylinder structures with appropriated domain sizes as required for organic photovoltaic devices, which will be present in a future study. In this communication the ATRP as a versatile route to a well-defined pol$\mathrm{y}$ (diethylhexyl- $p$-phenylenevinylene- $b$-styrene) (PPV$b$-PS) block copolymer is reported. The microphase separated morphologies obtained with this polymer are then studied to prove that this material fulfils the basic structural requirements for photovoltaic devices.

\section{EXPERIMENTAL}

\section{Materials}

Monomers (Aldrich, Saint Quentin Fallavier, France) were distilled on calcium hydride. 2-bromopropionyl bromide (Across, Organics, Halluin, France) and 2bromo-2-methylpropionyl bromide (Alfa Aeser, Schiltigheim, France) were used as received. Toluene and tetrahydrofurane (THF) was distilled on $\mathrm{Na}$ / benzophenone. PPV (1) was synthesized according to a published procedure. ${ }^{18,19}$ Afterward, it was purified by column chromatography on a silica gel (95\% cyclohexane, $5 \%$ of dichloromethane). Polydispersity index (PDI) was measured on gel permeation chromatography (GPC) and number-average molecular weight, $M_{n}$, was determined by nuclear magnetic resonance (NMR) using signal of proton from aldehyde end function at $10.3 \mathrm{ppm}$. (1) is dried by azeotropic distillation of toluene just before use. All other chemicals were purchased from Aldrich and used as received.

\section{Macroinitiators synthesis}

Typically, $0.95 \mathrm{~g}\left(0.28 \mathrm{mmol}\right.$ for a PPV with $M_{n}=$ $3400 \mathrm{~g} / \mathrm{mol}$ ) of dry PPV (1) are dissolved with 20 $\mathrm{mL}$ of dry THF under argon and stirring. The flask is cooled at $0^{\circ} \mathrm{C}$, and then, $2.5 \mathrm{~mL}(2.5 \mathrm{mmol})$ of solution of $\mathrm{LiAlH}_{4}(1 \mathrm{M}$ in THF) is carefully added. After $1 \mathrm{~h}$, the reaction is quenched with ethylacetate, and the mixture is filtered on cellite. Then, $20 \mathrm{~mL}$ of water are added and the organic layer is extracted with $150 \mathrm{~mL}$ of $\mathrm{CH}_{2} \mathrm{Cl}_{2}$ and washed three times with $50 \mathrm{~mL}$ of water. Organic layer is dried and evaporated. Dry product is dissolved in $5 \mathrm{~mL}$ of
$\mathrm{CH}_{2} \mathrm{Cl}_{2}$ and precipitated at $0^{\circ} \mathrm{C}$ in $100 \mathrm{~mL}$ of methanol. Product (2) is characterized by ${ }^{1} \mathrm{H}$ NMR (disappearance of aldehyde peak at $10.3 \mathrm{ppm}$, apparition of $\mathrm{CH}_{2}-\mathrm{OH}$ peak at $4.7 \mathrm{ppm}$ ) and by GPC with UV detection. Yield $=80 \%$.

In a second step, (2) is converted into (3) or (4). Typically, $0.74 \mathrm{~g}(0.22 \mathrm{mmol})$ of (2) is dissolved in 18 $\mathrm{mL}$ of ethanol-free $\mathrm{CH}_{2} \mathrm{Cl}_{2}$ and $3 \mathrm{~mL}$ of triethylamine. Then, 1.2 equivalent of 2-bromopropionyl bromide (for synthesis of 3) or 2-bromo-2-methylpropionyl bromide (for synthesis of 4 ) is added. The solution is stirred for $24 \mathrm{~h}$ under argon and then quenched with water. The product is extracted for three times with $20 \mathrm{~mL}$ of $\mathrm{CH}_{2} \mathrm{Cl}_{2}$. The organic layer is washed for three times with water, dried, and evaporated. Dry product is dissolved in $5 \mathrm{~mL}$ of $\mathrm{CH}_{2} \mathrm{Cl}_{2}$ and precipitated at $0^{\circ} \mathrm{C}$ in $100 \mathrm{~mL}$ of methanol. (3) and (4) are characterized by ${ }^{1} \mathrm{H}-\mathrm{NMR}$ (disappearance of $\mathrm{CH}_{2}-\mathrm{OH}$ peak at $4.7 \mathrm{ppm}$ ) and by GPC. The obtained yield was higher than $90 \%$.

Representative ${ }^{1} \mathrm{H}$ NMR $\left(\mathrm{CDCl}_{3}\right)$ spectra of (4): $\delta$ $(\mathrm{ppm})=7.6-7.0(m$, arom. $\mathrm{CH}, 4 \mathrm{n} \mathrm{H}), 4.2-3.7(m$, $\mathrm{OCH}_{2}, 4$ n protons), 2.5-0.7 ( $m$, aliph. $\mathrm{CH}, \mathrm{CH}_{2}$ and $\mathrm{CH}_{2}$ respectively, $2 \mathrm{n}$ protons, $16 \mathrm{n}$ protons, and $12 \mathrm{n}$ protons), where $m$ is the degree of polymerization of PPV.

\section{Rod-coil block copolymer synthesis}

A solution, typically between $5 \mathrm{~mL}$ and $10 \mathrm{~mL}$, of 1 equivalent of macroinitiator (3) or (4), 1 equivalent of $\mathrm{CuBr}, 1.1$ equivalent of 1,1,4,7,10,10-hexamethyltriethylenetetramine (HMTETA), $x$ equivalents of monomer, where $x$ is typically between 50 and 200, was prepared under argon and magnetic stirring. Depending on the conditions (bulk or solution), up to $50 \%$ (in weight) of toluene or other solvent can be added. After the formation of the complex (15 min), $2 \mathrm{~g}$ of the solution were placed in several glass tubes. After three freeze, thaw, pump cycles, the tubes were sealed under vacuum and placed in an oil bath (typically at $90^{\circ} \mathrm{C}$ ) for appropriate time. Once the polymerization reaction is accomplished, the solution is dissolved in dichloromethane, passed through a short alumina column and precipitated in methanol at $0^{\circ} \mathrm{C}$. The copolymer is dried 1 night in vacuum at $45^{\circ} \mathrm{C}$ and analyzed by gel permeation chromatography (GPC).

Representative ${ }^{1} \mathrm{H}$ NMR $\left(\mathrm{CDCl}_{3}\right)$ spectra of (5): $\delta$ $(\mathrm{ppm})=7.6-7.0(m$, arom. CH, PPV :4n protons and PS $5 m$ protons), $4.2-3.7$ ( $m, \mathrm{OCH}_{2}$, 4 n protons), 2.50.7 ( $m$, aliph. $\mathrm{CH}, \mathrm{CH}_{2}$, and $\mathrm{CH}_{3}$ of PPV, respectively, $2 \mathrm{n}$ protons, $16 \mathrm{n}$ protons, and $12 \mathrm{n}$ protons; and aliph $\mathrm{CH}, \mathrm{CH}_{2}$ of PS main chain, respectively $m$ protons and $2 m$ protons), where $n$ is the degree of polymerization of PPV block and $m$ the degree of polymerization of PS block. 


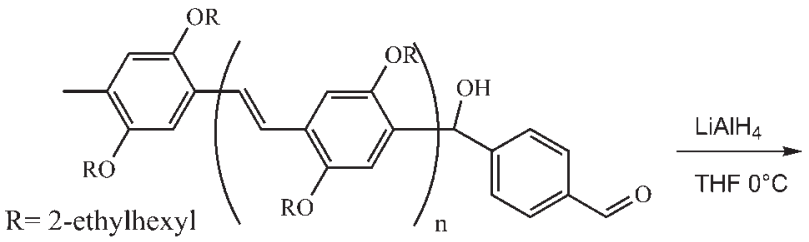

(1)

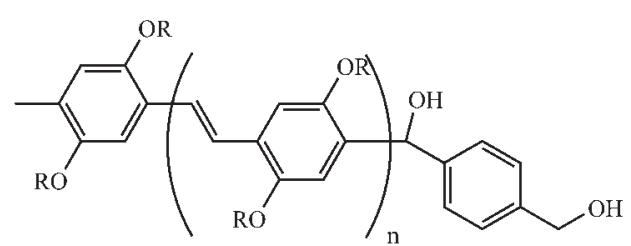

(2)

(4)
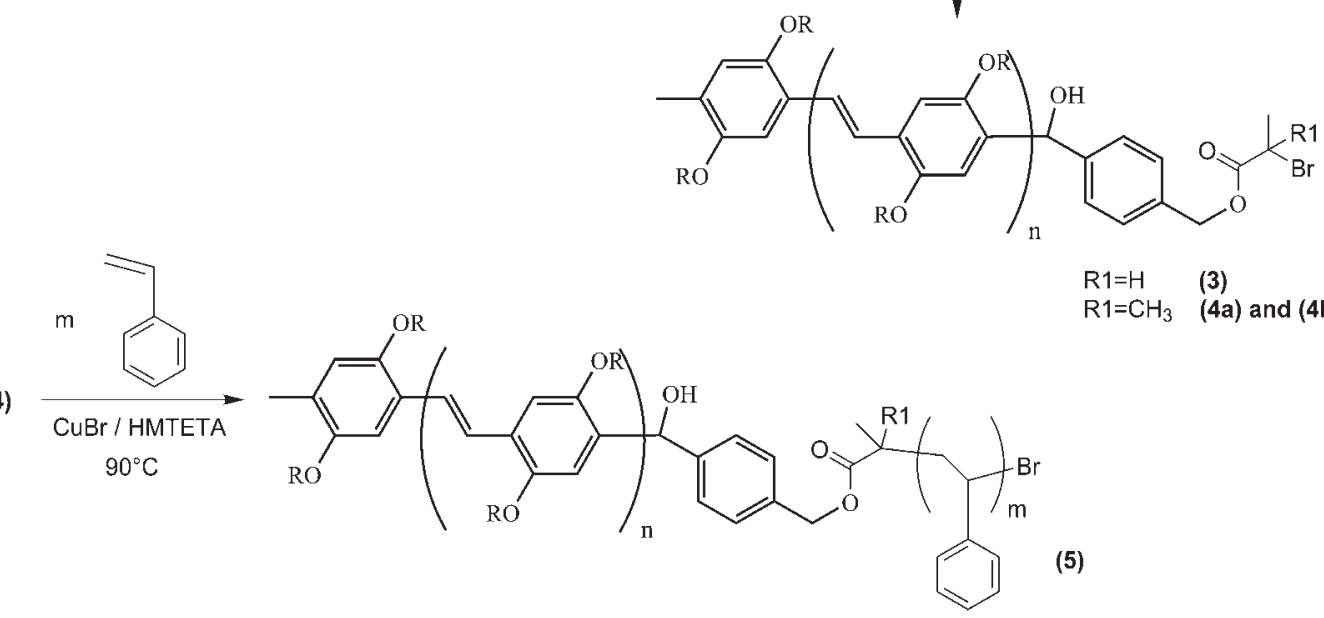

$\mathrm{R} 1=\mathrm{H} \quad$ (3) $\mathrm{R} 1=\mathrm{CH}_{3} \quad$ (4a) and (4b)

(5)

Scheme 1 Synthesis of PPV-based ATRP macroinitiators 3; $4 \mathbf{a}$ and $4 \mathbf{b}$; and synthesis of blocks copolymer 5.

\section{Characterizations}

${ }^{1} \mathrm{H}$ NMR spectra were recorded on a Bruker 300 UltrashieldTM $300 \mathrm{MHz}$ NMR spectrometer, with an internal lock on the $2 \mathrm{H}$-signal of the solvent $\left(\mathrm{CDCl}_{3}\right)$. GPC measurements were performed in THF with two PL-gel $5 \mu$ mixed-C, a $5 \mu 100 \mathrm{E}$, and a $5 \mu$ Guard columns in a Shimadzu LC-10AD liquid chromatograph equipped with a Shimadzu RID-10A refractive index detector and a Shimadzu SPP-M10A diode array detector. Complementary UV-Visible spectra have been recorded on a Shimadzu 2101PC spectrophotometer.

\section{Morphology study}

All samples are annealed in a high vacuum $(5 \times$ $10^{-12}$ bar) oven according to the following procedure: $4 \mathrm{~h}$ at $160^{\circ} \mathrm{C}$ and finally $72 \mathrm{~h}$ at $140^{\circ} \mathrm{C}$. These temperature steps are necessary to erase the thermal history of the samples and to maintain the blend in the temperature region comprised between the glass transition temperature of PS, $100^{\circ} \mathrm{C}$, and the orderdisorder transition temperature of mesophases based on rod/rod-coil self-assembly, so that the blend could achieve thermodynamic equilibrium.

All samples are embedded in a standard four components epoxy resin (46 wt \% Epon 812, 28 wt \% dodecenyl succinic anhydride, $25 \%$ nadic methyl anhydride, $1 \%$ (2,4,6-tris (dimethylaminomethyl) phenol) catalyst. To avoid diffusion of the resin components into the sample, the resin is precured 1.5 $\mathrm{h}$ at $80^{\circ} \mathrm{C}$ before embedding the sample. The sample is finally embedded in the precured epoxy resin, which was then let curing for $8 \mathrm{~h}$ at $60^{\circ} \mathrm{C}$. The samples are ultramicrotomed on a Reichert-Jung microtome at room temperature. The sections ( $60 \mathrm{~nm}$ thick) are collected on 300 hexagonal mesh copper grids (EMS $\mathrm{G} 300 \mathrm{H}-\mathrm{Cu}$ ). Staining of the PPV phase is achieved by exposing collected sections to vapors of $\mathrm{OsO} 4(0.5 \mathrm{wt}$ $\%$ salt in water) during $3 \mathrm{~h}$.

\section{RESULTS AND DISCUSSION}

\section{Synthesis}

ATRP macroinitiators are prepared from a monoaldehyde end-functionalized PPV $(\mathbf{1})^{18,19}$ with a low PDI. The synthesis process is summarized in Scheme 1. Two different kinds of initiators, 3 and 4 , are synthesized. For $\mathbf{4}$, two batches (4a and $\mathbf{4 b}$ ) are obtained, respectively, with $3400 \mathrm{~g} / \mathrm{mol}$ and $2700 \mathrm{~g} /$ mol (determined by NMR). Macroinitiators characteristics are summarized in Table I.

Block copolymers are synthesized by ATRP using 3 or 4 as macroinitiator (Fig. 1). Preliminary results, 
TABLE I

Macroinitiators Characteristics

\begin{tabular}{cccr}
\hline Macroinitiator & $\begin{array}{c}M_{n} \text { determined } \\
\text { by }{ }^{1} \mathrm{H} \mathrm{NMR} \\
(\mathrm{g} / \mathrm{mol})\end{array}$ & $\begin{array}{c}M_{n} \text { determined } \\
\text { by GPC } \\
(\mathrm{g} / \mathrm{mol})\end{array}$ & PDI $^{\mathrm{a}}$ \\
\hline $\mathbf{3}$ & 3100 & 4400 & 1.3 \\
$\mathbf{4 a}$ & 3400 & 5600 & 1.2 \\
$\mathbf{4 b}$ & 2700 & 3100 & 1.3 \\
\hline
\end{tabular}

${ }^{\text {a }}$ Measured by GPC with PS standards.

not reported here, with various monomers (styrene, methyl and butyl acrylates) showed a better reactivity of 4 for the initiation of the second block. For this study, work has been focused on the polymerization of styrene as model monomer using the most reactive initiator (4). Furthermore, PS-based copolymers are good model block copolymers for the morphology study. Results of copolymerization are summarized in Table II.

Run A is carried out in bulk and leads to an insoluble rubbery red material after $30 \mathrm{~h}$. At lower polymerization times, the formation of a soluble polymer with low PDI is observed. When the monomer is diluted in toluene ( $\mathrm{B}$ and $\mathrm{C}$ ) the polymerization is slower, whereas crosslinking is not avoided but only delayed. In each case, the PDI is lower than 1.5 in the early stage of polymerization, molecular weight grows with conversion and the experimental $M_{n}$ fits with the theoretical value calculated from conversion and initiator amount. The slight difference between theoretical and experimental molecular weights can be attributed to the GPC measurement obtained from PS standards, which is not exactly adapted for these copolymers. However, $M_{n}$ evolution is progressive with time and is nearly linear with conversion. Furthermore, GPC traces of copolymerization

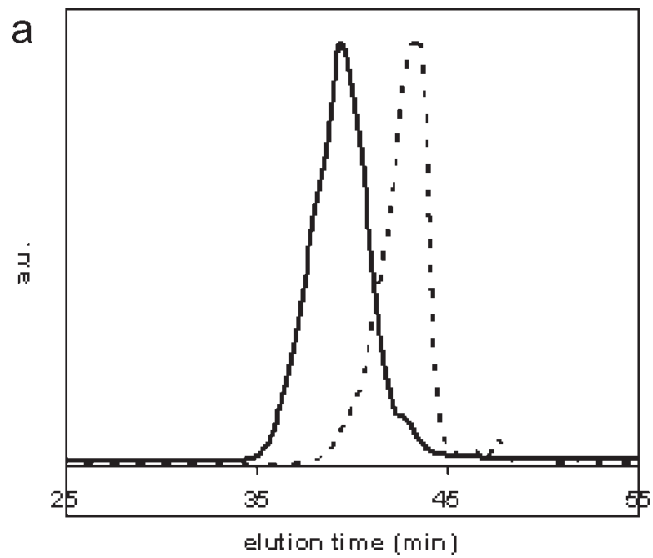

Figure 1 GPC traces for styrene ATRP with 4, Runs $x, y$ h. (a) UV detection at $480 \mathrm{~nm}$ and (b) RI detection. Copolymerization product 5 (-) and PPV macroinitiator $4(---)$.

product and PPV macroinitiator (Fig. 1) shows the disappearance of 4 with RID detector [Fig. 1(a)] as well as with UV detection at $480 \mathrm{~nm}$ [Fig. 1(b)], where only PPV is detected. The very small peak corresponding to 4 , represents less than $2 \%$ of the total PPV, calculated from the peak areas with detection at $480 \mathrm{~nm}$, whereas more than $98 \%$ of the PPV have initiated copolymer chains. Furthermore, UV/ visible spectra, obtained from GPC DAD detector, of PPV initiator and block copolymer (Fig. 2) confirm that PPV block is well incorporated in copolymer. All these observations lead to the conclusion that polymerization shows a living character and that most of the side reactions are avoided, yielding to the product 5 .

The increase of PDI at higher conversions, and finally the crosslinking, can be attributed to side reactions on the PPV block. Indeed, transfer or termination reactions of PS macroradicals on the PPV block may induce crosslinking reactions. The exact nature of these side reactions has not been investigated in this study, however, a radical reaction of living PS chains on the vinylene PPV double bond could be a reasonable hypothesis. Decreasing temperature can minimize these side reactions but requires very high polymerization time. However, at lower conversion, the copolymer molecular weight distribution is narrow and UV/visible spectra confirm the incorporation of PPV block in the final product without its alteration. This kind of side reactions are also observed with NMRP macroinitiators; however, they were prevented using much larger [monomer]/[initiator] (decreasing dramatically initiator concentration) ratio and lower conversion. ${ }^{20}$ ATRP polymerization with PPV macroinitiators cannot totally avoid side reactions, but, due to mild reaction conditions, polymerization of the second block is better controlled at much higher conversion

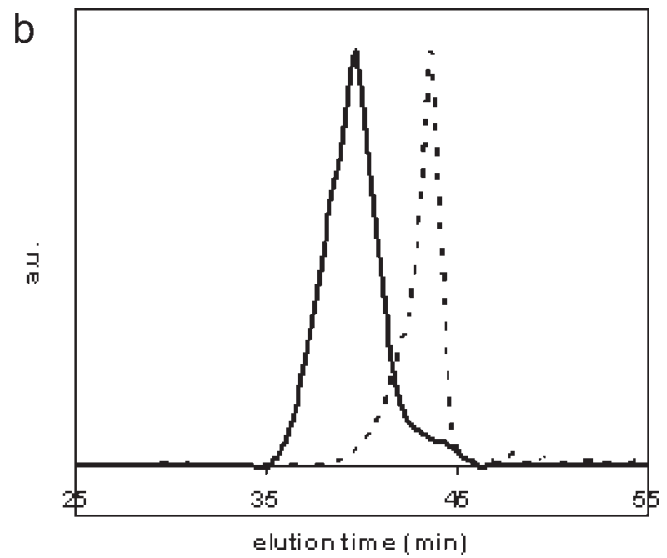


TABLE II

Results for Styrene ATRP with PPV Macroinitiator at $90^{\circ} \mathrm{C}$ with 1 eq of $\mathrm{CuBr} / \mathrm{HMTETA}$ as Catalyst

\begin{tabular}{|c|c|c|c|c|c|c|c|}
\hline Run & Initiator & {$[\mathrm{M}]_{0} /[\mathrm{I}]_{0}$} & Reaction time $(\mathrm{h})$ & Yield (\%) & Theoretical $M_{n}(\mathrm{~g} / \mathrm{mol})^{\mathrm{a}}$ & $M_{n}(\mathrm{~g} / \mathrm{mol})^{\mathrm{b}}$ & $\mathrm{PID}^{\mathrm{b}}$ \\
\hline \multirow[t]{3}{*}{$\mathrm{A}^{\mathrm{c}}$} & $4 a$ & 200 & 15.5 & 30 & 9,600 & 14,100 & 1.5 \\
\hline & & & 23 & 51 & 14,000 & 17,000 & 1.5 \\
\hline & & & 30 & Gel & - & $29,100^{d}$ & $1.3^{\mathrm{d}}$ \\
\hline \multirow[t]{3}{*}{$\mathrm{B}^{\mathrm{e}}$} & $4 b$ & 100 & 8 & 18 & 4,600 & 6,400 & 1.5 \\
\hline & & & 16.3 & 40 & 6,900 & 10,700 & 2.1 \\
\hline & & & 72 & Gel & - & - & - \\
\hline \multirow[t]{3}{*}{$C^{e}$} & $4 b$ & 100 & 8 & 16 & 4,400 & 5,800 & 1.4 \\
\hline & & & 11 & 27 & 5,500 & 7,100 & 1.5 \\
\hline & & & 21.8 & 34 & 6,200 & 11,000 & 2.3 \\
\hline
\end{tabular}

${ }^{a}$ Calculated from yield, monomer and initiator ratio, and PPV molecular weight.

b Measured by GPC with PS standards.

${ }^{c}$ Polymerization in bulk.

d Soluble fraction.

e Polymerization in toluene (50\% in weight).

than NMRP at $125^{\circ} \mathrm{C}$. PPV-b-PS Copolymers obtained by ATRP also exhibiting relatively low PDI, good correlation between experimental and theoretical $M_{n}$ and good reinitiation ratio (at least $98 \%$ of PPV macroinitiator reinitiate) are less controlled than the on obtained by anionic route. ${ }^{14}$ Especially, the presence of homo-PPV polymer cannot be avoided with ATRP due to the intrinsic mechanisms of this controlled radical polymerization. Moreover, whereas ATRP limit the achievable molecular masses, we reported $\mathrm{Mn}$ above $20000 \mathrm{~g} / \mathrm{mol}$ by anionic route, for the same block copolymer without evidence of any side reactions. However, the anionic polymerization is less versatile considering the range of monomers, which can be used, and is far more demanding on the experimental conditions than the ATRP. Thus, the route presented here provides if not perfect control, an easy synthetic path to a wide range of PPV based bloc copolymers.

\section{Morphological study}

The samples characterized with TEM and presented on the micrographs in Figure 3 are from the polymerization runs $\mathrm{B}$ and $\mathrm{C}$. These $\mathrm{B}$ and $\mathrm{C}$ runs correspond to block copolymers with the same rod block but various coil sizes. $M_{n}$ of coil block is limited to the range from $3100 \mathrm{~g} / \mathrm{mol}$ to $5600 \mathrm{~g} / \mathrm{mol}$, as measured with GPC, corresponding to coil volume fraction between 53 and $66 \%$, respectively. The structure variation in this range of volume fraction proved to be very abrupt: $13 \%$ increase of the coil volume fraction is sufficient to transform a long range ordered lamellar structure into a mainly isotropic sample.

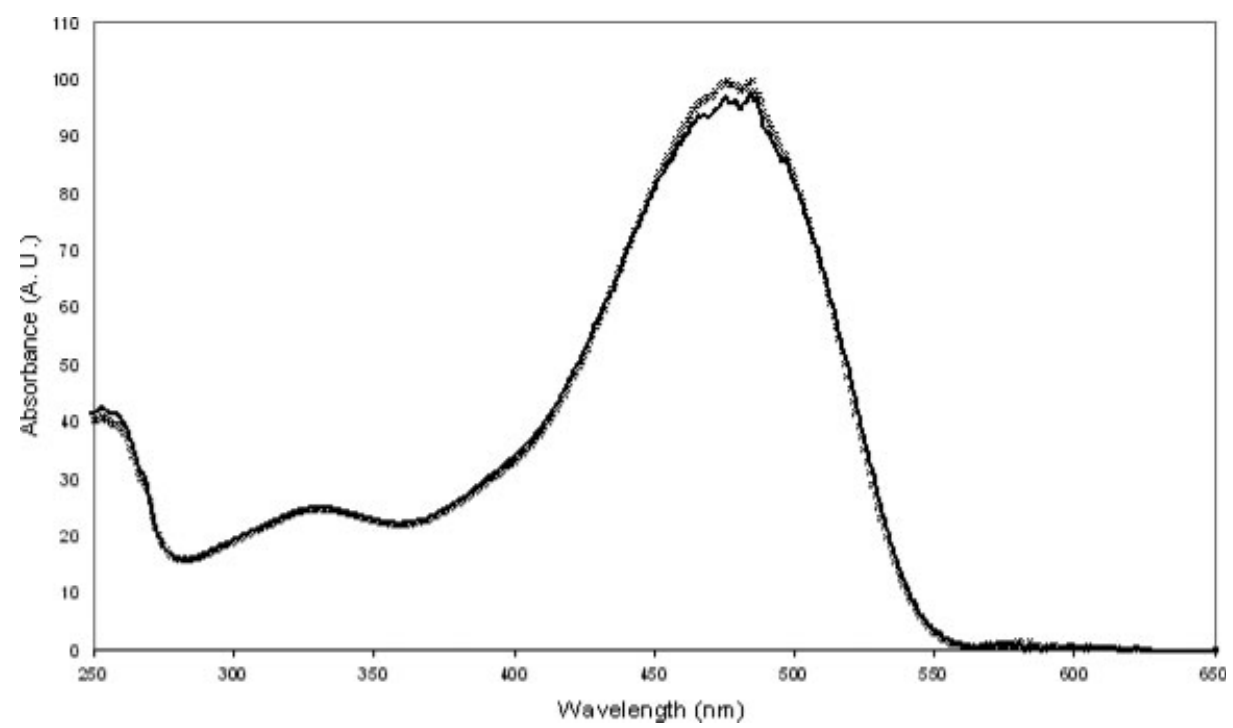

Figure 2 UV/visible spectra of 5 (-) and PPV macroinitiator $4(\times \times \times)$ obtained with DAD detector from GPC chromatograms, respectively at $\mathrm{RT}=39.4 \mathrm{~min}$ and $\mathrm{RT}=43.0 \mathrm{~min}$. 

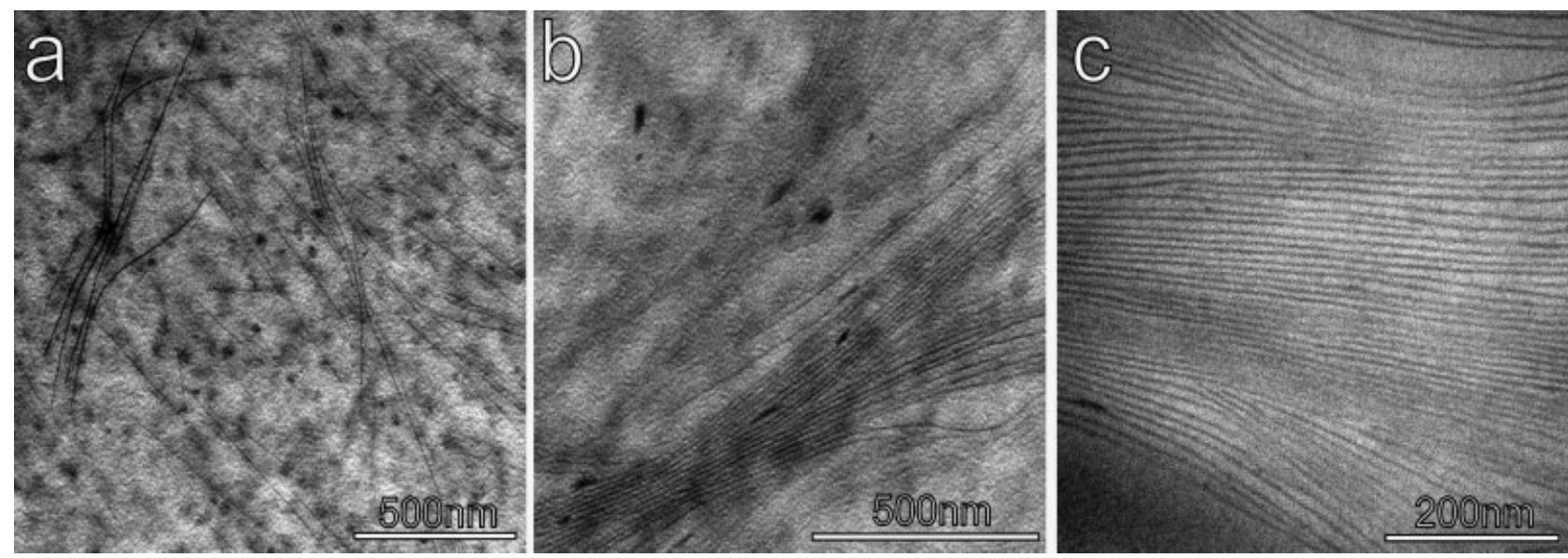

Figure 3 TEM pictures for sample with overall molecular mass (a) $8000 \mathrm{~g} / \mathrm{mol}$, (b) $6400 \mathrm{~g} / \mathrm{mol}$, and (c) $5800 \mathrm{~g} / \mathrm{mol}$. Lowest molecular weight polymers, i.e., ones with the larger rod overall fraction, exhibit long range ordered lamellae, a slight increase in coil volume fraction induce a loss of long range order. When the coil size if further increased, a transition to an essentially isotropic phase is observed, without any evidence of an hexagonal or spherical intermediate phase.

The observed sharp variation is explained by competing tendencies to microphase separate and to form liquid crystalline PPV rich domains. We have shown that PS- $b$-PPV copolymers have a behavior typical of a weak segregated system with high liquid-crystalline interactions. ${ }^{32,33}$ At temperatures above the glass transition temperature of polystyrene $\left(100^{\circ} \mathrm{C}\right)$, for which thermodynamic equilibrium structures can be achieved by thermal annealing, only the region corresponding to the lamellar phase of the rod-coil block copolymer phase diagram is accessible. Consequently, nonlamellar morphologies as expected ${ }^{31}$ cannot be achieved in the weakly segregated regime typical of PPV-PS block copolymers studied here. The rod nature of one of the two blocks, further imposes liquid crystallinity of the rod blocks, resulting in smectic lamellar phases. Actually, higher order-disorder transition temperature and better organization cannot be achieved by increasing both block sizes: long-range structure could only be obtained in the PS-PPV system with short coil blocks. To synthesize these copolymers, ATRP polymerization method reported here, proven to be particularly well suited.

\section{CONCLUSIONS}

Synthesis of well-defined model PPV-b-PS copolymer has been achieved by a versatile controlled/ "living" radical polymerization. Side reactions are avoided by limiting the conversion of the polymerization. Furthermore a large improvement has been shown concerning the reducing of the side reactions comparing with NMRP route.

TEM images have shown microphases segregation of the copolymers leading to self-assembly materials. Despite a relatively low coil size variation, the poly- mers synthesized exhibit dissimilar structures ranging from long-range order to isolated clusters. This observation can be explained by competing tendencies to microphase separation and liquid crystalline behavior. This behavior is mainly due to the chemical similarity of PS and PPV as well as the rod nature of the PPV block.

ATRP method constitutes a powerful simple tool for the synthesis of well-defined copolymers. Its versatility permits to work in mild conditions which are required to minimize radical side reactions on PPV block. In future work, introduction of functional monomers, during the polymerization reaction of the coil block will be achieved, to incorporate electron acceptor units.

\section{References}

1. Brabec, C. J.; Saraciftci, N. S.; Hummelen, J. C. Adv Funct Mater 2001, 11, 15.

2. Coakley, K. M.; McGehee, M. D. Chem Mater (review) 2004, $16,4533$.

3. Saraciftci, N. S.; Smilowitz, L.; Heeger, A. J.; Wudl, F. Science 1992, 258, 1474

4. Granström, M.; Petritsch, K.; Arias, A. C.; Lux, A.; Andersson, M. R.; Friend, R. H. Nature 1998, 395, 257.

5. Schmidt-Mende, L.; Fechtenkötter, A.; Müllen, K.; Moons, E.; Friend, R. H.; MacKenzie, J. D. Science 2001, 293, 1119.

6. McFarland, E. W.; Tang, J. Nature 2003, 421, 616.

7. Brabec, C. J Sol Energy Mater Sol Cells 2004, 83, 273.

8. Heeger, A. J. Rev Modern Phys 2001, 73, 681.

9. Bates F. S.; Frederickson, G. H. Phys Today 1999, 52, 32.

10. Sun, S.-S. Sol Energy Mater Sol Cells 2003, 79, 257.

11. Krebs, F. C.; Hagemann, O.; Jørgensen, M. J Sol Energy Mater Sol Cells 2004, 83, 211.

12. Lindner, S. M.; Thelakkat, M. Macromolecules 2004, 37, 8832.

13. Segalman, R. A.; Brochon, C.; Hadziioannou, G. In Organic Photovoltaics: Mechanisms, Materials, and Devices; Sam-Shajing, S.; Niyazi Serdar, S., Eds.; Taylor \& Francis: USA, 2005; p 403. 
14. Sary, N.; Mezzenga, R.; Brochon, C.; Hadziioannou, G.; Ruokolainen, J. Macromolecules 2007, 40, 3277.

15. Olsen, B. D.; Segalman, R. A. Macromolecules 2005, 38, 10127.

16. de Boer, B.; Stalmach, U.; van Hutten, P. F.; Meltzer, C.; Krasnikov, V. V.; Hadziioannou, G. Polymer 2001, 42, 9097.

17. Stalmach, U.; de Boer, B.; Videlot, C.; van Hutten, P. F.; Hadziioannou, G. J Am Chem Soc 2000, 122, 5464.

18. Stalmach, U.; de Boer, B.; Post, A. D; van Hutten, P. F.; Hadziioannou, G. Angew Chem Int Ed 2001, 40, 428.

19. Kretzschmann, H.; Meier, H. Tetrahedron Lett 1991, 32, 5059.

20. van der Veen, M. H.; de Boer, B.; Stalmach, U.; van de Wetering, K. I.; Hadziioannou, G. Macromolecules 2004, 37, 3673.

21. Mihaela, C. I.; Malika Jeffries, E. L.; Elena, E. S.; Jessica, R. C.; McCullough, R. D. Polymer 2005, 46, 8582.

22. Liu, J.; Sheina, E.; Kowalewski, T.; McCullough, R. D. Angew Chem Int Ed 2002, 41, 329.

23. Marsitzky, D.; Klapper, M.; Mullen, K. Macromolecules 1999, 32,8685 .
24. Lu, S.; Fan, Q. L.; Chua, S. J.; Huang, W. Macromolecules 2003, 36, 304

25. van de Wetering, K.; Brochon, C.; Ngov, C.; Hadziioannou, G. Macromolecules 2006, 39, 4289

26. Tosolakis, P.; Kallitsis, J.; Godt, A. Macromolecules 2002, 35, 5758.

27. Chochos, C.; Kallitsis, J.; Gregoriou, V. J Phys Chem B 2005, 109,8755 .

28. Heiser, T.; Adamopoulos, G.; Brinkmann, M.; Giovanella, U.; Ould-Saad, S.; Brochon, C.; van de Wetering, K.; Hadziioannou, G. Thin Solid Films 2006, 511-512, 219.

29. Hawker, C.; Bosman, A.; Harth, E. Chem Rev 2001, 101, 3661.

30. Matyjaszewski, K.; Xia, J. H. Chem Rev 2001, 101, 2921.

31. Qu, G.; Jiang, F.; Zhang, S.; Usuda, S. Mater Lett 2007, 61, 3421.

32. Sary, N.; Brochon, C.; Hadziioannou, G.; Mezzenga, R. Eur Phys J E 2007, 24, 379.

33. Reenders, M.; Ten Brinke, G. Macromolecules 2002, 35, 3266. 